\title{
Education and the Political Economy of Environmental Protection
}

\author{
Natacha Raffin*
}

August 21, 2009

\begin{abstract}
We develop a model where agents decide wether to invest in additional education according to their expectations regarding future environmental quality. Then, agents vote on a tax that will be used exclusively to finance environmental protection. Under the assumption of rational and constant expectations, the model may generate multiple equilibria. Moreover, we show that agents'expectations regarding future environmental quality may be self-fulfilling when the public policy is endogenous. This paves the way for a public intervention. Hence, we analyse the long-run dynamic implications of a policy in favour of education, in order to select the higher equilibrium.
\end{abstract}

JEL classification: .

Keywords: .

\section{Introduction}

Recently, environmental issues have become a great interest to economists, policy-makers and citizens, in general. This came along with the emergence of a "green" awareness, more lobbying or even the birth of ecological political groups. This recent evolution may be explained by a lot of both socio-economic and political factors like, for instance, income, health, education, age, sex, democracy, etc. (see Fredriksson et al. (2005), Farzin \& Bond (2006)). Focusing on the relationship between the level of education and this stronger concern for the environment, we can observe a positive causal link at a microeconomic level.

In particular, using the data from the World Value Survey ${ }^{1}$ allows us to establish a positive link between the level of education and the level of green consciousness, when dealing with environmental actions. For instance in OECD countries, at the positive statement "would give a part of my income for the environment", we can see that upper educated agents answer in average more often "agree" or "strongly agree" than middle or lower educated individuals (see Figure 1a below).

\footnotetext{
*Paris School of Economics, CES - Université Paris 1 Panthéon-Sorbonne; 106-112, bd. de l'Hôpital, F-75013 Paris (France). Ph.: +33 (0)1 44078213. E-mail: natacha.raffin@univ-paris1.fr.

1. The World Value Survey consists in a study dealing with "values and cultural changes in societies all over the world". The data are available on the following web site: http://www.worldvaluessurvey.org/. Individuals are asked to answer a wide range of assertions concerning their own cultural values. Reported answers are ranged from "strongly agree" to "strongly disagree".
} 


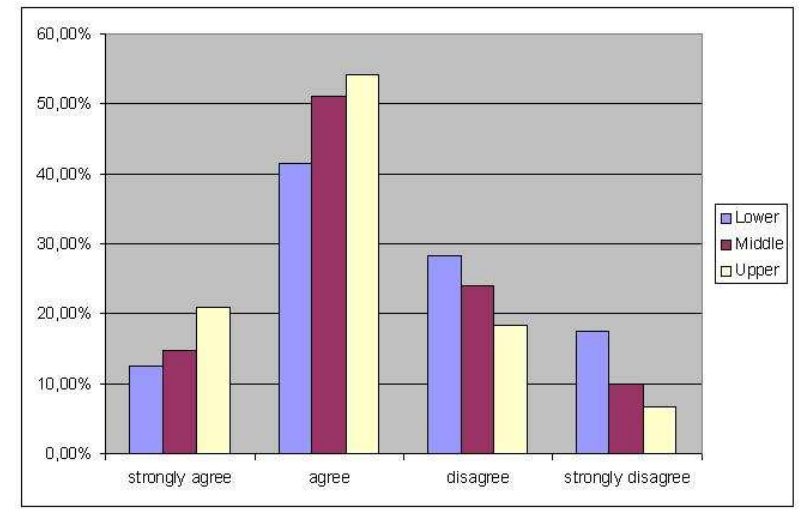

(a) "..give a part of income.."

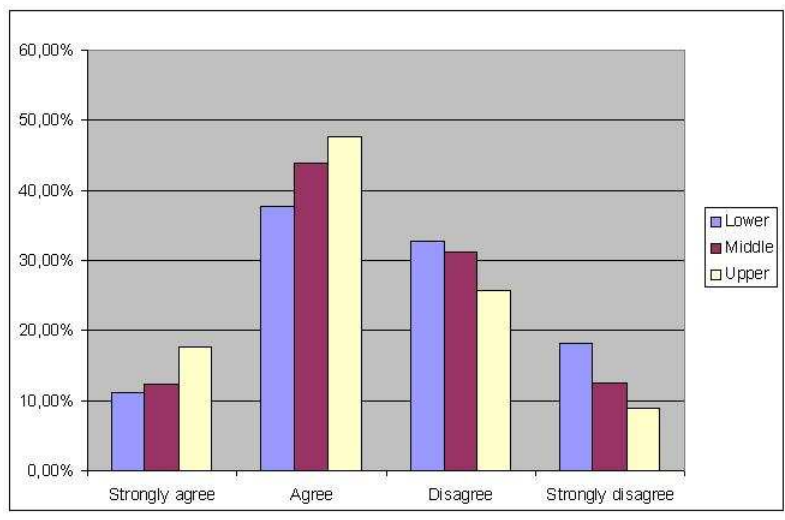

(b) "..increase in tax.."

Figure 1. World Value Survey data dealing with environmental actions

More precisely, we observe that around $64 \%$ of upper educated agents are likely to spend monetary resources to protect or clean the environment, while the share of lower educated agents who are opposed to such expenditures amounts to more than $45 \%$. Similarly, from the assertion "increase in taxes if used to prevent environmental pollution", we can identify a positive relationship between the level of education and the desire to increase the fiscal pressure in order to protect environmental conditions (see Figure $1 \mathrm{~b}$ ). In particular, we observe that the share of upper educated agents that are in favour of such politics is the highest one $(17,80 \%$ "strongly agree" and 47,80\% "agree"), while it becomes the lowest one when the answer turns out to be "disagree" $(25,7 \%)$ or "strongly disagree" $(8,8 \%)$.

At an aggregate level, these findings imply that environmental quality may crucially depend on the distribution of skills within the population. A country where the share of highly educated agents is large, is more likely to engage it-self in environmental protection or more prone to accept a heavier environmental fiscal pressure. The present model aims at capturing this mechanism through a model of political economy.

We propose a theoretical setting where agents decide themselves about their education. All individuals face the same fixed cost of education in order to acquire basic skills, whereas they differ in their capacity to get additional human capital. Once, they choose their level of education, they vote for a tax that finances environmental protection. Multiple equilibria may occur because of the dynamic interplay between political and economic decisions. Moreover, our model also allows us to discuss a rational public intervention in favor of education as a strategic way to shift political power and select a higher equilibrium.

In the model, we consider a continuum of two-period lived agents who get utility from consumption and environmental quality. During adulthood, when all relevant decisions are taken, they share their time endowment between education and work. Once agents acquired basic skills, they may directly supply to the market unskilled labour force. Alternatively, they can also choose to provide skilled workforce by investing in additional human capital. In addition, we consider that educated workers exhibit a higher life expectancy. The key ingredient of our setting is that life expectancy determines the marginal utility of the environment: agents who expect to live longer exhibit stronger concern for the environment since they will benefit from it longer. Consequently, choices of education depend ultimately on agents' expectations with re- 
spect to future environmental quality. When individuals anticipate deteriorated environmental conditions at next date, they have few incentive to invest in additional human capital and the proportion of unskilled workers within the population increases. Conversely, when they expect a good future environmental quality, they are likely to bear an extra cost of education, to benefit longer from the environment when old.

Once occupational choices are made, agents vote on the level of the poll tax, which will be used to finance public environmental maintenance. It is shown that optimal willingnessto-pay for the environment depends crucially on education and so on longevity: a higher life expectancy increases the level of the preferred tax, by raising stronger concern for the environment, while it reduces private consumption. This result may be backed up by compelling evidence, like Goetz (1998), Carlsson \& Johansson-Stenman (2000), Brock \& Taylor (2005), that highlight the important role played by both socio-demographic and economic factors, including the level of education or health status, in explaining the positive correlation between the level of education and the public support for environmental protection.

We consider a simple majority voting mechanism so that the political outcome depends on the current distribution of traits within the population. Hence, if the majority within the economy is unskilled, the implemented environmental tax is the lower one, and conversely. In turn, as previously exposed, the median voter's feature is it-self affected by future environmental quality. This dynamic interaction between the economic and political decisions of individuals may generate multiple equilibria and indeterminacy. In particular, we show that agents' expectations regarding future environmental quality may be self-fulfilling as the public policy is endogenous. Hence, the coordination on one outcome allows for multiple equilibrium paths with different long-run consequences in terms of environmental quality and development. On the one hand, if expectations are coordinate on thinking the future environmental quality to be good, there is a room for an equilibrium path that self-confirms these anticipations: the economy is lead in the long-run towards a high equilibrium characterized by both good environmental quality and a more highly educated population. On the other hand, if expectations are more pessimistic with respect to future environmental quality, then skilled workers are a minority. The resulting effort of maintenance provided publicly is smaller and confirms initial expectations: the economy may be caught in a trap featured by a poor environment and a majority of unskilled workers.

Finally, the crucial role played by agents' expectations paves the way for a public intervention in order to select the higher equilibrium. Accordingly, we assess the dynamic consequences of a public policy that aims at stimulating education in order to escape from the trap. Among many available instruments, we choose to model the impact of a reduction in the fixed cost of education. The public policy is still endogenous, but the tax is now used for two alternative purposes: education and environmental maintenance. We show that if initially the economy is trapped, this policy may at first deteriorates the environment, but in a second step allows the economy to reach the higher equilibrium, characterized by improved environmental conditions. In addition, we emphasize that the public policy may be temporary although it has permanent effects in the long-run.

At an aggregate level, some empirical data may support our conclusions, such that more educated economies display better environmental performance. Indeed, using data from the Center for International Development (CID (2000)) on the secondary school enrollment in 2000 
and the Environmental Index Performance ${ }^{2}$ (YCELP (2006)), we can observe a positive correlation, as shown in Figure 2, between the two variables.

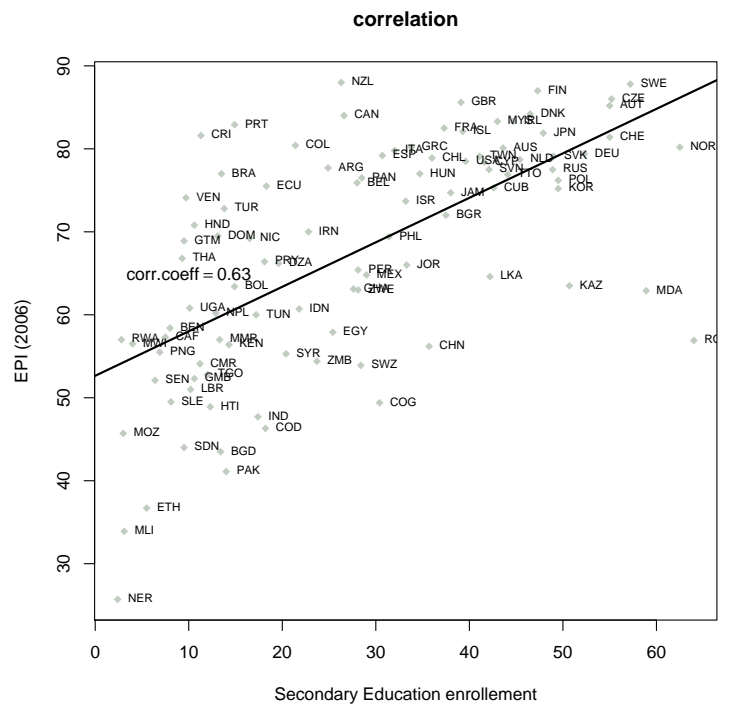

Figure 2: Correlation between second school enrollment and environmental performance

Our paper is related to those articles that have analysed environmental issues in dynamic OLG framework. In particular, we refers to the setting proposed by John \& Pecchenino (1994) or Ono (2002) to describe the evolution of environmental quality over time. A link can also be established with the paper of Ikefuji \& Horii (2007) who identify a poor-environment trap associated with a low level of human capital or the one by Mariani et al. (2009) where the trap is also characterized by a lower life expectancy. However, our anlaysis contrasts with those papers as we consider the effort of maintenance being provided publicly, as a consequence of a political equilibrium. On the contrary, Jouvet et al. (2008) consider the trade-off between private and public environmental spending, although agents differ, in their framework, in their behaviour with respect to bequest.

This article is also built on recent models of expectations-driven multiplicity like Saint Paul \& Verdier (1997), Bisin \& Verdier (2000) or Hauk \& Saez-Marti (2002), although we concentrate on more environmental dynamical issues, rather than the mechanism of preferences transmission. Nevertheless, similarly to these papers we investigate the opportunities of public intervention in order to select a unique equilibrium. In this respect, our paper may also be related to the article of Glomm \& Ravikumar (1995), who study the dynamic implications of equilibrium selection.

The remainder of the paper is organised as follows. In Section 2, we introduce the model

2. The EPI index was built as a synthetic index of environmental performance. It includes various factors, going from "environmental health" (indoor pollution, drinking water, adequate sanitation and urban particulates) to "ecosystems vitality" (air quality, water and productive natural resources, biodiversity). Data are available on-line at http:/ / epi.yale.edu. 
and analyse the dynamic behaviours of the economy. Policy implications are discussed in Section 3 and Section 4 concludes.

\section{The basic model}

\subsection{Individual behaviour}

Let consider an overlapping generations model where individuals live for two periods: adulthood and old age. Time is discrete, $t=0,1, \ldots+\infty$. At any date $t$, there is a continuum of agents of mass 1 being born. Accordingly, no population growth is considered. Lifespan utility of an agent $i$, at date $t$, writes as:

$$
U_{t}^{i}=c_{t}^{i}+\pi_{t}^{i} E_{t+1}
$$

It is defined over private consumption $\left(c_{t}\right)$ during adulthood and environmental quality $\left(E_{t+1}\right)$ when old. In our setting, agents could have valued the environment during their first period of life; however, as we will see below, their choices with respect to the current environmental conditions do not affect the environment so that the results hold unchanged. Besides, savings have not been introduced as we do not focus so far on the relationship between physical capital accumulation and the environment.

Utility derived from the second period of life is discounted by a factor $\pi_{t}^{i} \in(0,1]$ which accounts for life expectancy or longevity ${ }^{3}$. In this set-up, it could also be regarded as the weight given by agents to main environmental concerns so that, it could be interpreted as the level of green preferences. It is worth noticing that here, those preferences would be endogenous since we consider that life expectancy of an individual $i$ depends crucially on occupational choices. More precisely, we argue that longevity is widely explained by the level of income (without focusing on the feedback effect of life expectancy on the income it-self): richer agents have better access to health services, adequate living conditions, are more educated, likely to adopt healthier behaviours etc. (see, for instance, Barro \& Sala-i Martin (1995), Chakraborty (2004), de la Croix \& Licandro (2007) or Lleras-Muney (2005)). Formally, this assumption implies that: $\pi_{t}^{i} \equiv \pi\left(w_{t}^{i}\right)$, where $w_{t}^{i}$ is the wage rate earned by an individual $i$ during adulthood and such that $\pi^{\prime}(\cdot)>0, \pi^{\prime \prime}(\cdot)<0$ and $\lim _{w_{t}^{i} \rightarrow+\infty} \pi(\cdot)=1$.

During their first period of life, each agent is endowed with one unit of time, which can be shared among education and work. All individuals spend a fixed period of time at school, $\lambda \in(0,1)$, in order to acquire basic skills. Once they get this primary knowledge, they can supply directly unskilled labour to the market. However, they also may become skilled, through acquisition of additional human capital. Individual rather than their parents decide about their education so that, the choice of acquiring human capital implies a trade-off: human capital allows for a higher wage while it requires a loss in the valuable time, $z$. Let us suppose that this time cost is distributed uniformly within the population on the range $[0,1]$. As in Cervellati \& Sunde (2005), this parameter $z$ may be interpreted as innate abilities in terms of learning capacities. However, in our model, individual abilities affect the cost of education rather than its return. Consequently, a high $z$ implies lower abilities such that the time spent to educate is

3. Here, these two terms will be used interchangeably since both concepts exhibit similar properties. It could be either a probability of surviving to the old age or the length of the second period of life, thus being include in the interval $(0,1]$. In either case, the benefit drawn from the future state of the environment is distorted by a time-length factor. 
longer and the remaining time working on the market, shorter. Then, the net labour income $\left(y_{t}^{i}\right)$ for both types of existing workers, during adulthood, is given by:

$$
\left\{\begin{array}{l}
y_{t}^{s}=(1-\lambda-z) w_{t}^{s} \\
y_{t}^{u}=(1-\lambda) w_{t}^{u}
\end{array}\right.
$$

where $i=\{s, u\}$, for skilled workers and unskilled workers, respectively. In the end, one good is produced (and privately consumed) using only one input, labour. Both kinds of workforce are perfectly substitute, so that:

$$
Y_{t}=A_{t}^{s} H_{t}+A_{t}^{u} L_{t}
$$

where $H_{t}$ represents the aggregate skilled workforce (so called human capital) and $L_{t}$ the aggregate unskilled labour available in the economy. Let us notice that production could be realized thanks to only one type of labour, either skilled or unskilled. Moreover, $A_{t}^{i}$ represents the productivity level in each sector. We assume that $A_{t}^{s}>A_{t}^{u}$ since we want to capture the greater capacity of educated agents to adopt and apply a given technology, to learn additional knowledge: it is less "costly" to adapt to advanced technologies being already educated (for further discussion see, among others, Fershtman et al. (1996), Caselli (1999), Galor \& Moav (2000)).

Besides, so as the market is competitive, each input is paid to its marginal productivity and wages are fully shaped by the stock of knowledge in the considered sector. Therefore, there exists a skill premium for educated workers, which involves a positive wage gap between both kinds of occupations. From (3), wage rates are deduced:

$$
\left\{\begin{array}{l}
w_{t}^{s}=A_{t}^{s} \\
w_{t}^{u}=A_{t}^{u}
\end{array}\right.
$$

Agents use their labour income to consume but are also subjected to a poll tax ${ }^{4}\left(\tau_{t}\right)$. Since environmental quality is mostly a public good and costs required to abate pollution very high, individuals or groups within the population are unable to effectively provide them. Then we consider that this tax is levied by the government in order to alleviate pollution, to improve or, at least, maintain environmental quality. However, the environmental policy implemented by the government is party influenced by preferences of individuals within the society. Accordingly, in our framework, we consider a political equilibrium where agents take an active part in the decision-making process concerning the design of the environmental policies, by voting on the level of such an environmental tax. Finally, all decisions are taken during the first period of life and the budget constraint writes as:

$$
y_{t}^{i}-\tau_{t}=c_{t}^{i}
$$

This green tax, used by the government, affects considerably the evolution of environmental quality over time. In fact, following the seminal works of John \& Pecchenino (1994) or Ono (2002), the law of motion of environmental quality can be expressed as:

$$
E_{t+1}=(1-\eta) E_{t}-P_{t}+\beta g\left(\tau_{t}\right)
$$

4. Of course, it could be the case that the environmental tax is proportional to the wage; however, as we will see later, in that case, choices of additional education would depend on both expectations regarding future environmental quality, but also expectations about the future tax rate. Moreover, the preferred tax rate it-self would depend on wages, and so would be distributed within the population of educated agents. Finally, this would heavily complicate the analysis. 
with $0<\eta<1$ is the natural depreciation rate of the environment, $P_{t}$, harmful pollution flows, $g\left(\tau_{t}\right)$, the environmental maintenance provided by authorities and $\beta>0$, the efficiency of such environmental expenditure. Let us underline that here, agents value the environment that may encompass environmental conditions (going from air quality to quality of water, soils etc.) as well as resources availability (like, for instance, biodiversity, forestry, fisheries and so on..). Broadly speaking, this variable $E_{t}$ is multidimensional and can be regarded as an indicator of all amenities provided by the nature ${ }^{5}$.

Furthermore, it is worth noticing that in our set-up, maintenance outcome account only for the next period so that adults' choices with respect to the environment can not affect directly current environmental conditions, although pollution flows are instantaneous. Indeed, the natural environment and most kinds of ecosystems may react slowly to green measures; then, environmental changes are postponed and often occur after a long period.

The goal pursued by the government is to improve environmental quality (this coud be also a direct reduction of pollution). Then, tax revenue are used to finance maintenance (i.e., abatement) expenditure:

$$
g\left(\tau_{t}\right)=\tau_{t}^{\theta}
$$

with $\theta \in(0,1]$, which could embody the efficiency of the maintenance technology. Here, tax revenue translate into maintenance, but we consider that this maintenance technology exhibits decreasing marginal returns: as tax receipts rise, the marginal efficiency of abatement reduces. Alternatively, this parameter $\theta$ could be regarded as the efficiency of government institutions, meaning that a low value of $\theta$ induces a larger wasted part of tax receipts. Tax revenue may be partly dissipated in collection costs; otherwise said, marginal collection costs increase in the tax rate, due, for instance, to the existence of bureaucratic inefficiencies (Saint Paul \& Verdier (1997), Lightart \& Ploeg (1999)). In the end, both interpretations of $\theta$ also induce that utility is concave in environmental maintenance and so satisfies usual properties: individuals face a trade-off between private consumption and future environmental quality.

Using equation (4), we can derive the life expectancy of each type of worker, so that:

$$
\pi\left(w_{t}^{i}\right)= \begin{cases}\pi\left(A_{t}^{s}\right) & \text { if } i=s \\ \pi\left(A_{t}^{u}\right) & \text { if } i=u\end{cases}
$$

As discussed above and through the properties of $\pi(\cdot)$, we can state that $\pi\left(A_{t}^{s}\right)>\pi\left(A_{t}^{u}\right)^{6}$.

An individual $i$ with a time consuming cost equal to $z$ is indifferent between educate himself or not if, for a given green tax,

$$
U_{t}^{s}=U_{t}^{u} \Leftrightarrow\left[(1-\lambda-z) w_{t}^{s}-\tau_{t}\right]+\pi\left(A_{t}^{s}\right) E_{t+1}=\left[(1-\lambda) w_{t}^{u}-\tau_{t}\right]+\pi\left(A_{t}^{u}\right) E_{t+1}
$$

A threshold value on $z$, the time cost, is deduced from the above equality:

$$
\tilde{z}_{t}=\frac{(1-\lambda)\left(A_{t}^{s}-A_{t}^{u}\right)+\left[\pi\left(A_{t}^{s}\right)-\pi\left(A_{t}^{u}\right)\right] E_{t+1}^{a}}{A_{t}^{s}},
$$

\footnotetext{
5. Notice that $E_{t}$ is an index of environmental values that can take either positive or negative values.

6. In fact, we consider here that life expectancy is fully determined by the wage rate rather than the income. Although we consider a quite simple hypothesis, this does not affect qualitatively our main results. Indeed, whatever the case, life expectancy of skilled workers is always larger than the one of uneducated workers. Once again, if life expectancy was affected by income, it would also depend on the educational time cost, $z$. Then, the chosen poll tax $\tau_{t}$ and life expectancy $\pi\left(A_{t}^{i}\right)$ would be distributed among the population of skilled workers, thus complicating the formal analysis.
} 
with $E_{t+1}^{a}$, the expected future state of the environment. Indeed, agents choose wether to educate or not when young and so, have to anticipate future environmental conditions when they decide about their additional education. Furthermore, the static comparison of utility (see equation (9)) implies that for any distributed $z \leq \tilde{z}_{t}$, agents choose to acquire additional knowledge; conversely, if $z>\tilde{z}_{t}$, individuals do not invest in further education and provide unskilled labour force.

Given that $z$ is uniformly distributed within the population, the aggregate labour supplies of both types of workers, at date $t$, are given by:

$$
H_{t}=\int_{0}^{\tilde{z}_{t}} d z=\tilde{z}_{t}
$$

and

$$
L_{t}=\int_{\tilde{z}_{t}}^{1} d z=\left(1-\tilde{z}_{t}\right)
$$

Here, $\tilde{z}_{t}$ is exactly the proportion within the population that does educate. Obviously, if $\tilde{z}_{t}$ is very high that is for $E_{t+1}^{a} \geq \hat{E} \equiv \frac{\lambda\left(A_{t}^{s}-A_{t}^{u}\right)+A_{t}^{u}}{\left[\pi\left(A_{t}^{s}\right)-\pi\left(A_{t}^{u}\right)\right]}$, everybody educates (i.e. the proportion of highly educated agents equals unity); when $E_{t+1}^{a}=0$, there still exists a positive share of agents that spend time educating, $\tilde{z}_{t}=(1-\lambda)\left(A_{t}^{s}-A_{t}^{u}\right) / A_{t}^{s}$. Finally, when expected environmental quality is very low, $E_{t+1}^{a} \leq \check{E} \equiv \frac{-(1-\lambda)\left(A_{t}^{s}-A_{t}^{u}\right)}{\left[\pi\left(A_{t}^{s}\right)-\pi\left(A_{t}^{u}\right)\right]}$, nobody educates.

Not surprisingly, this threshold value $\tilde{z}_{t}$ reduces with $\lambda$, the fixed cost of primary education, while as depicted on Figure (3), it depends positively on agents' expectations regarding the future state of the environment: individuals are prone to suffer a higher cost of education if they anticipate improved future environmental conditions. In fact, an expected good environmental quality is an incentive to educate, to benefit longer from the environment when old, all the more so as the longevity gap is large.

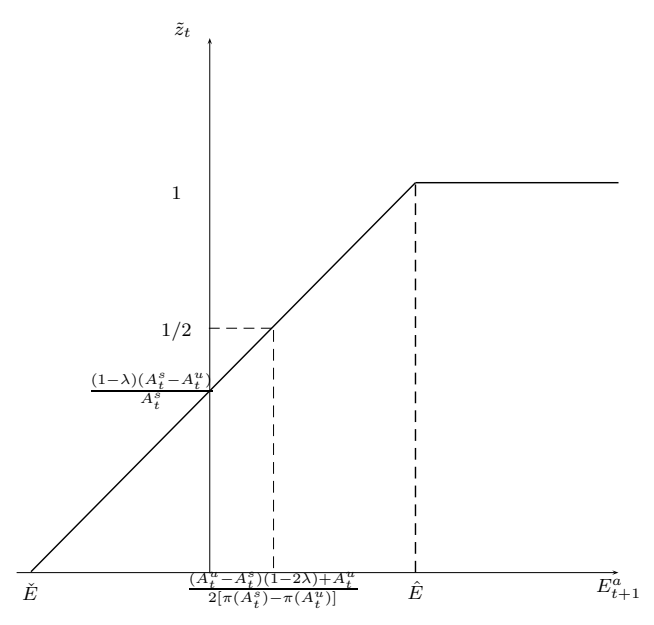

Figure 3: share of skilled agents within the population 
However, the global impact of the technological level in the skilled sector $\left(A_{t}^{s}\right)$ is not clear cut. In particular, a rise in $A_{t}^{s}$ exhibits positive income and longevity effects. When the technology improves, productivity (and wages) of highly educated agents increases, thus implying that a skilled worker is likely to bear a larger educational cost. In addition, life expectancy is positively influenced by the stock of knowledge in the skilled sector, thus reinforcing the enhancing role played by the expected environmental quality on the choice of education. Conversely, it turns out that education is costly and the higher the income, the larger the opportunity cost of additional education. Finally, since environmental quality provides a fixed utility gain to agents, net of the longevity effect, $A_{t}^{s}$ also implies a dilution effect that tends to slacken the extra investment in human capital and reduce the share of type-s workers within the population. Indeed, the net utility derived from the environment is reduced by this opportunity cost, which is obviously higher for agents with lower abilities, i.e., higher $z$. Otherwise said, the net utility of the environment must be high enough to compensate for the loss of available labour income when agents choose to acquire additional education.

Furthermore, using equations (11) and (12), the production in the economy can be rewritten as:

$$
Y_{t}= \begin{cases}A_{t}^{u} & \text { if } E_{t+1}^{a} \leq \check{E} \\ \tilde{z}_{t}\left(A_{t}^{s}-A_{t}^{u}\right)+A_{t}^{u} & \text { if } \breve{E}<E_{t+1}^{a}<\hat{E} \\ A_{t}^{s} & \text { if } E_{t+1}^{a} \geq \hat{E}\end{cases}
$$

When all workers are skilled, production is fully determined by the level of the technology in the skilled sector, while it becomes fully determined by the technology in the unskilled sector when nobody educates; when both types of workers co-exit, we can see that the share of skilled individuals in the economy boosts production.

Finally, let consider that pollution flows in the economy arise from the production process ${ }^{7}$ such that: $P_{t}=\gamma Y_{t}$, with $0<\gamma \leq 1$, which reveals the cleanness degree of production: the higher $\gamma$, the dirtier the production. Here we neglect the fact that pollution intensity may differ from one sector to an other (from one kind of labour to an other, as in Ikefuji \& Horii (2007)), but we consider a production-induced pollution. In this respect, it could be quite similar to consider that pollution is associated with consumption flows in the economy. In the end, using equation (13), it follows that pollution flows in the economy may be expressed as:

$$
P_{t}= \begin{cases}\gamma A_{t}^{u} & \text { if } E_{t+1}^{a} \leq \check{E} \\ \gamma\left[\tilde{z}_{t}\left(A_{t}^{s}-A_{t}^{u}\right)+A_{t}^{u}\right] & \text { if } \check{E}<E_{t+1}^{a}<\hat{E} \\ \gamma A_{t}^{s} & \text { if } E_{t+1}^{a} \geq \hat{E}\end{cases}
$$

Since a rise in the proportion of highly educated workers stimulates both production (equation 13) and pollution (equation 14), a feedback effect of environmental quality arises: optimistic expectations regarding the future state of the environment trigger extra-investment in education, which in turn, by increasing the share of skilled workers, induces more pollution and so more pressure on the environment. Finally, the net impact of agents' expectations on environmental quality will depend crucially on the effort of maintenance provided by the government and on the tax adopted within the society.

7. We consider here a linear relationship between pollution flows and production for the sake of simplicity. 


\subsection{Political equilibrium}

As mentioned before, the poll tax is exclusively used to provide environmental maintenance expenditure. The government's budget is balanced, so that tax receipts equal:

$$
\tilde{z}_{t} \tau_{t}+\left(1-\tilde{z}_{t}\right) \tau_{t}=\tau_{t}
$$

Beyond the benefit derived from an improved environment, the tax reduces the available income of agents during youth: as already mentioned, each individual faces a trade-off between private consumption and future environmental quality. Once they decide about their education, agents aim at maximising their lifetime utility under equations (5) and (6) in order to determine their optimal willingness-to-pay for environmental preservation. From the first-order condition, we obtain the optimal poll tax for an individual $i$ in a decentralized equilibrium:

$$
\tau_{t}^{i}=\left(\beta \pi\left(A_{t}^{i}\right) \theta\right)^{\frac{1}{1-\theta}} .
$$

It is worth noticing that this optimal willingness-to-pay for the environment is fully determined by the technology through life expectancy, which might differ according to the type of agent. Provided that $\pi\left(A_{t}^{s}\right)>\pi\left(A_{t}^{u}\right)$, it follows obviously that $\tau_{t}^{s}>\tau_{t}^{u}$ and environmental quality is well a normal good. Hence, a stricter environmental policy may be implemented in an economy where the share of skilled agents is larger. Otherwise said, high-income agents are more prone to pay for environmental protection. This result may be related to some theoretical papers that identify various key determinants to justify such microeconomic behaviour. For instance, Plassmann \& Khanna (2006) define some general properties on consumers preferences and on the pollution function that lead, in the end, to a reduction in pollution as income increases; Renström \& Marsiliani (2002) show that a higher marginal rate of substitution between environment and private consumption induces ultimately a higher environmental tax. Similarly, Pfaff et al. (2004) shows that low-income agents prefer not to abate pollution according to their marginal rate of substitution. This optimal microeconomic choice may also refer to the conclusion of Andreoni \& Levinson (2001) who highlight the fact that higher income individuals aim at consuming more, but also polluting less. In addition, our result is consistent with widespread empirical evidence such that higher income or/and higher level of education rise stronger concern for the environment by improving health and life expectancy (Goetz (1998), Carlsson \& Johansson-Stenman (2000), Brock \& Taylor (2005)). Finally, highly educated agents display longer life expectancy and so are likely to contribute for preserving the environment. In addition, this result may be linked to empirical data that suggest a positive correlation between environmental quality and life expectancy as in Mariani et al. (2009): longer longevity raises concern for the future, while in turn, life expectancy may increase when the environment is less deteriorated.

As individuals exhibit single-peaked preferences with respect to the environmental tax, the theorem of the median voter holds. Therefore, the political outcome depends on the the median voter's feature (skilled or unskilled) and writes as:

$$
\left\{\begin{array}{l}
\tau_{t}=\tau_{t}^{u} \text { if } E_{t+1}^{a}<\tilde{E} \\
\tau_{t}=\tau_{t}^{s} \text { if } E_{t+1}^{a} \geq \tilde{E}
\end{array}\right.
$$

with

$$
\tilde{E} \equiv \frac{A_{t}^{u}-A_{t}^{s}(1-2 \lambda)+A_{t}^{u}}{2\left[\pi\left(A_{t}^{s}\right)-\pi\left(A_{t}^{u}\right)\right]}
$$


where $\tilde{E}$ is defined as the level of $E_{t+1}^{a}$ such that $\tilde{z}_{t}=1 / 2$.

The poll tax effectively chosen is crucially affected by agents'expectations with respect to environmental quality. If $E_{t+1}^{a}$ is low, less agents invest in education and the share of unskilled workers is greater than a half $\left(\tilde{z}_{t}<1 / 2\right)$. The converse is true if $E_{t+1}^{a}$ is high. Agents are prone to suffer a higher extra cost of education: the share of skilled workers rises, the median voter becomes skilled $\left(\tilde{z}_{t} \geq 1 / 2\right)^{8}$. Accordingly, the demand for environmental protection raises and the green tax becomes higher.

\subsection{Dynamics}

Substituting (10), (14) and (16) into the law of motion of environmental quality, we obtain a system that describes the global dynamical behaviour of the economy. For ease of presentation, we assume hereafter that technical progress in the economy is constant, thus $A_{t}^{i}$ is set equal to $A^{i}$. This restriction allows us to present the main insights and results of our model more intuitively. Following equation (8) and since technical progress is constant over time, it turns out that life expectancy becomes also invariant over time, $\pi\left(A^{i}\right)$. Similarly, as optimal poll taxes are fully shaped by the life expectancy (see equation (16)), they also turn to be constant.

Depending on the median voter's feature, we can characterize the dynamics of the economy. In particular, when the median voter is unskilled, we define $E_{t+1} \equiv \psi_{u}\left(E_{t}, E_{t+1}^{a}\right)$ so that

$$
\psi_{u}\left(E_{t}, E_{t+1}^{a}\right)= \begin{cases}(1-\eta) E_{t}-\gamma A^{u}+\beta \tau^{u^{\theta}} & \text { if } E_{t+1}^{a} \leq \check{E} \\ (1-\eta) E_{t}-P\left(E_{t+1}^{a}\right)+\beta \tau^{u^{\theta}} & \text { if } E_{t+1}^{a}>\check{E},\end{cases}
$$

with $P\left(E_{t+1}^{a}\right)$ is a function describing pollution flows according to the value of $\tilde{z}_{t}$ that, in turn, depends mainly on agents'expectations regarding the future state of the environment, $E_{t+1}^{a}$. Alternatively, when the median voter is skilled, we define $E_{t+1} \equiv \psi_{s}\left(E_{t}, E_{t+1}^{a}\right)$ such that

$$
\psi_{s}\left(E_{t}, E_{t+1}^{a}\right)= \begin{cases}(1-\eta) E_{t}-P\left(E_{t+1}^{a}\right)+\beta \tau^{s^{\theta}} & \text { if } E_{t+1}^{a} \geq \hat{E} \\ (1-\eta) E_{t}-\gamma A^{s}+\beta \tau^{s^{\theta}} & \text { if } E_{t+1}^{a}<\hat{E} .\end{cases}
$$

Finally, the global dynamics can be summarized by:

$$
E_{t+1}= \begin{cases}\psi_{u}\left(E_{t}, E_{t+1}^{a}\right) & \text { if } E_{t+1}^{a}<\tilde{E} \\ \psi_{s}\left(E_{t}, E_{t+1}^{a}\right) & \text { if } E_{t+1}^{a} \geq \tilde{E}\end{cases}
$$

The dynamics are crucially affected by expectations agents have about the future environment. These anticipations influence the share of skilled workers within the population and simultaneously determine the type of the median voter: using equation (16), we can see that only for fairly high values of $E_{t+1}^{a}$, the median voter becomes skilled. In fact, if agents anticipate good future environmental conditions, they choose to educate, since they expect to benefit longer from the environment, through a longevity effect. As the proportion of type-s workers increases, the median voter is likely to be skilled. However, because pollution flows are positively correlated with the share of highly educated workers in the economy, agents' expectations translate

8. Notice that here, there exists a usual problem when $\tilde{z}=1 / 2$ to determine which group wins the elections. In order to avoid this, and for the sake of simplicity, we simply assume that when $\tilde{z}=1 / 2$, the winner majority is skilled. 
into more pressure on the environment (see equation (14)), all the more so as the proportion of skilled agents is high. Finally, optimistic expectations may be harmful for the environment, through the effect of pollution flows but may become beneficial to it only through a "cliquet" effect, that is when the economy shifts from one regime to an other. For instance, if initially the majority is unskilled, a rise in the share of highly educated workers (through optimistic expectations) induces more damage on the environment. But, as $\tilde{z}_{t}$ increases, it could be the case that skilled workers becomes majority: the implemented tax is thus higher and environmental quality may be improved. Broadly speaking, a reduction in $\tilde{z}_{t}$ does not induce mechanically a lower pressure on the environment, rather than the effort of maintenance may be reduced.

\subsubsection{Perfect foresight dynamics}

In order to solve the dynamics, we assume that agents perfectly anticipate future environmental conditions, thus inducing that $E_{t+1}^{a}=E_{t+1}$. Under this assumption, the perfect foresight dynamics of the economy is obtained by solving equation (21) for $E_{t+1}^{a}=E_{t+1}$. Hence, we get a one-dimensional dynamical system that describes the evolution of environmental quality over time:

$$
E_{t+1}= \begin{cases}\Psi_{u}\left(E_{t}\right) & \text { if } E_{t+1}<\tilde{E} \\ \Psi_{s}\left(E_{t}\right) & \text { if } E_{t+1} \geq \tilde{E}\end{cases}
$$

with:

$$
\Psi_{u}\left(E_{t}\right)= \begin{cases}(1-\eta) E_{t}-\gamma A^{u}+\beta \tau^{u^{\theta}} & \text { if } E_{t+1} \leq \check{E} \\ \frac{A^{s}\left[(1-\eta) E_{t}+\beta \tau^{u^{\theta}}\right]-\gamma(1-\lambda)\left(A^{s^{2}}+A^{u^{2}}\right)+\gamma A^{u} A^{s}(1-2 \lambda)}{A^{s}+\gamma\left(A^{s}-A^{u}\right)\left(\pi^{s}-\pi^{u}\right)} & \text { if } \check{E}<E_{t+1}<\tilde{E}\end{cases}
$$

and

$$
\Psi_{s}\left(E_{t}\right)= \begin{cases}\frac{A^{s}\left[(1-\eta) E_{t}+\beta \tau^{s^{\theta}}\right]-\gamma(1-\lambda)\left(A^{s^{2}}+A^{u^{2}}\right)+\gamma A^{u} A^{s}(1-2 \lambda)}{A^{s}+\gamma\left(A^{s}-A^{u}\right)\left(\pi^{s}-\pi^{u}\right)} & \text { if } \tilde{E} \leq E_{t+1}<\hat{E} \\ (1-\eta) E_{t}-\gamma A^{s}+\beta \tau^{s^{\theta}} & \text { if } E_{t+1} \geq \hat{E}\end{cases}
$$

where $\pi^{i}$ stands for $\pi\left(A^{i}\right)$, for ease of presentation.

The global perfect foresight dynamics (see equation 22) are in two parts differing by the median voter's feature. The following lemma states that each part of the dynamics taken separately is characterized by a unique and globally stable steady-state.

Lemma 1 Under proper conditions, each dynamic trajectory, $\Psi_{u}\left(E_{t}\right)$ or $\Psi_{s}\left(E_{t}\right)$, admits only one globally stable steady-state, $E^{u}$ and $E^{s}$, characterized by a low and a high environmental quality, respectively.

\section{Proof. See Appendix A}

In our framework a steady-state is defined as a fixed point $E^{i}$ with $i=\{s, u\}$ such that: $E_{t+1}=E_{t}$. In particular, using equations (23) and (24), for $\breve{E}<E_{t+1}<\hat{E}$, we will have that:

$$
\begin{aligned}
& E^{u}=\frac{A^{s}\left[\beta \tau^{u^{\theta}}\right]-\gamma\left[(1-\lambda)\left(A^{s^{2}}+A^{u^{2}}\right)-A^{s} A^{u}(1-2 \lambda)\right]}{\gamma\left(A^{s}-A^{u}\right)\left(\pi^{s}-\pi^{u}\right)+\eta A^{s}} \\
& E^{s}=\frac{A^{s}\left[\beta \tau^{s^{\theta}}\right]-\gamma\left[(1-\lambda)\left(A^{s^{2}}+A^{u^{2}}\right)-A^{s} A^{u}(1-2 \lambda)\right]}{\gamma\left(A^{s}-A^{u}\right)\left(\pi^{s}-\pi^{u}\right)+\eta A^{s}},
\end{aligned}
$$


where $E^{s}>E^{u}$, since $\tau^{s}>\tau^{u}$. ${ }^{9}$ Since the median voter's feature depends, in turn, on the future environmental quality, the model may provide the conditions for the existence of multiple equilibria. Indeed, using Lemma 1, as depicted in Figure 4, we can claim that:

Proposition 1 Let assume that agents have rational expectations, then

(i) $E_{t}$ always converges towards $E^{u}$, if $\underline{E}>E^{s}$;

(ii) $E_{t}$ always converges towards $E^{s}$, if $\bar{E}<E^{u}$;

(iii) when $\underline{E}<E^{u}<E^{S}<\bar{E}$, there always exist stationary expectations such that:

- if $E_{0}<\tilde{E}, E_{t+1}=\Psi_{u}\left(E_{t}\right)$ and $E_{t}$ converges towards $E^{u}$

- if $E_{0} \geq \tilde{E}, E_{t+1}=\Psi_{s}\left(E_{t}\right)$ and $E_{t}$ converges towards $E^{s}$

Proof. See Appendix B

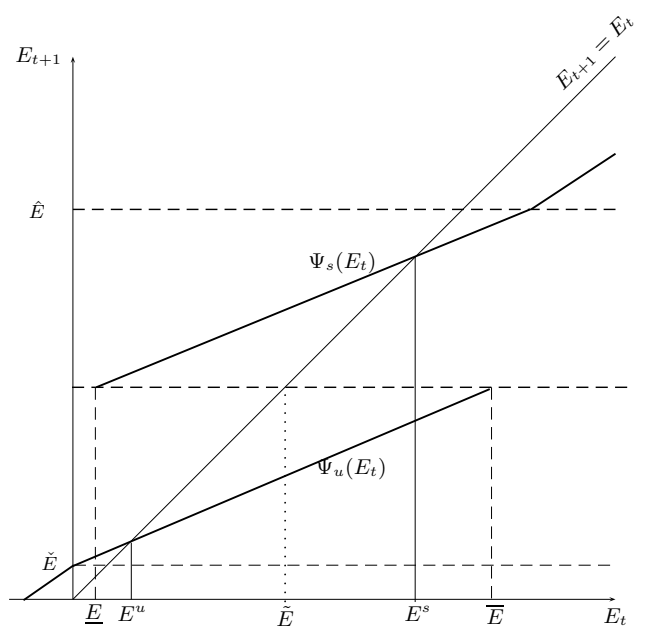

Figure 4: Multiple equilibria, case (iii) of Proposition 1

Part (i) of Proposition 1 is likely to arise when efficiency of maintenance expenditures $(\beta)$ or the level of that $\operatorname{tax} \tau^{u}$ are high enough with respect to $\gamma$, the cleanness degree of production. In that case the effect of environmental expenditure is highly beneficial to the environment and both harmful pollution flows and environmental depreciation effects are more easily counterbalanced. Environmental quality improves and, no matter initial conditions, the economy converges towards the unique and high equilibrium $E^{s}$. Conversely, part (ii) occurs for a very dirty production, that is when $\gamma$ tends to one. This may prevent the high equilibrium from

9. It is worth noticing that for $E_{t+1} \leq \check{E}, E^{u}=\frac{\beta \tau^{u^{\theta}}-\gamma A^{u}}{\eta}$ and $E_{t+1} \geq \hat{E}, E^{S}=\frac{\beta \tau^{\tau^{\theta}}-\gamma A^{s}}{\eta}$. However, we choose to report in the text the solutions depicted in Figure 4. 
existing and the only stable steady-state in the economy is $E^{u}$. In that case, both dynamics are shifted downward, so that $E^{u}$ is even lower.

Part (iii) of Proposition 1 is depicted in Figure 4. When the two steady-states co-exist, then, depending on initial conditions, the economy may converge towards either $E^{u}$ or $E^{s}$. If initially, environmental quality is somewhat low (for $E_{0}<\tilde{E}$ ), majority is unskilled so as the median voter. Under the assumption of stationary expectations, anticipations are and remain quite pessimistic, and inventives to educate weak. Then, the tax which is implemented is lower and the economy converges toward $E^{u}$, following the trajectory described by the function $\Psi_{u}\left(E_{t}\right)$. The resulting stationary value of environmental quality is low and the share of unskilled workers within the population is large. In that case, we can say the economy is caught in an environmental trap featured by a damaged environmental quality and a low level of development. Conversely, if initially the environment is good (for $E_{0} \geq \tilde{E}$ ), the median voter is skilled. Stationary expectations are optimistic and incentives to invest in extra education are boosted. The level of maintenance provided publicly is higher and the economy reaches $E^{s}$, a stationary value characterized by improved environmental conditions and a more educated population. In our framework, an increase in the proportion of skilled workers does not imply necessarily a heavier pressure on the environment. In fact, it also induces a rise in the environmental maintenance provided by public authorities. Yet, as discussed above, this latter effect overcomes the former and so environmental quality at the high steady-state is well improved compared to the trap.

These multiple equilibria, linking environmental quality and level of education, can be backed up by some empirical evidence, which show that more educated economies are likely to exhibit better environmental conditions (see, for instance, Magnani (2000), Bimonte (2002), Fredriksson et al. (2005), Farzin \& Bond (2006)). As shown previously, this positive relationship may be micro-founded. In particular, a higher level of education may in it-self trigger stronger concern for the environment (Goetz (1998), Carlsson \& Johansson-Stenman (2000), Brock \& Taylor (2005)), encouraging the emergence of a green consciousness. At an aggregate level, this greater awareness of environmental issues can be explained by the existence of more willingness and ability to express environmental preferences through existing channels, like lobbying groups, non-governmental organizations, voting etc....

\subsubsection{Indeterminacy and self-fulfilling equilibria}

As we saw, the political outcome depend on agents' expectations and the model may generate multiple equilibria. As in Bisin \& Verdier (2000) or Hauk \& Saez-Marti (2002), we consider that expectations are no longer stationary, and then study the dynamic implications of agents coordination on a particular expectation regarding future environmental quality. We can then claim that:

Proposition 2 Expectations might be self-fulfilling since two different values of $E_{t+1}$ may be compatible with a unique value of $E_{t}, \forall E_{t} \in[\underline{E}, \bar{E}]$.

\section{Proof. See Appendix C}

Interestingly, our model exhibits equilibria with self-fulfilling expectations as claimed in Proposition 2. This implies that when, initially, the state of population is relatively balanced, the role of expectations and their coordination on a particular future outcome become a key ingredient for the determination of long-run evolutions of environmental quality. Consider, for 
instance, a situation where initially agents of type- $u$ are a majority and $E_{t} \in[\underline{E}, \bar{E}]$. If all of them are pessimistic and thus expecting that future environmental quality will stay damaged, the share of unskilled workers remains majority. The resulting effort of maintenance is thus small and self-confirms initial expectations. Consequently, if agents coordinate on this same pessimistic belief all along the dynamical process, the environment converges towards $E^{u}$, where skilled workers are a minority. Conversely, starting from the same situation, that is a majority of unskilled workers within the population but if agents coordinate on a more optimistic view of the future environment, the stationary value of environmental quality may be improved. In fact, agents are more likely to invest in additional education for them-selves: type-s workers may become the majority and the tax equals $\tau^{s}$, thus increasing the level of maintenance. Again, expectations are realised while environmental quality reached by the economy is better. Moreover, unskilled workers turn out to be minority.

Proposition 2 defines an indeterminacy area, in which expectations may be self-confirmed. An interesting configuration occurs when one, or both equilibria $\left(E^{u}\right.$ and $\left.E^{s}\right)$ belong to this area. Indeed, as stated in Proposition 1, these stationary values are stable under stationary expectations; but, they may be destabilized following a change in expectations. The Corollary below summarizes this result:

Corollary 1 When $E^{s}$ and $E^{u} \in[\underline{E}, \bar{E}]$, one economy that would have converge towards the low equilibrium under the assumption of stationary expectations, may instead reach the higher steady-state value $E^{s}$ thanks to a change in the expectations' feature (be it optimistic), and conversely.

As described in Figure 4, for some range of values of environmental quality, $E_{t} \in[\underline{E} ; \bar{E}]$, two dynamic trajectories co-exist. When both steady-states belong to this area of indeterminacy, one economy that would have otherwise converged towards $E^{u}$ (under pessimistic stationary expectations), might instead, by means of change in expectations, jump on $\Psi_{s}\left(E_{t}\right)$ and attain the high stationary value of the environment, $E^{S}$. In this case, switching from pessimistic expectations to more optimistic ones allows to escape from the initial poor-environment trap. This mechanism works also in the opposite way, so that an economy initially located in $E^{u}$ (under the assumption of stationary expectations) might, in the end, be pushed towards the low equilibrium, if anticipations become suddenly pessimistic.

In our setting, the change in agents'expectations is a possible way, among others, to switch the trajectories followed by one economy. As pointed out by some other theoretical papers like Glomm \& Ravikumar (1995), Bisin \& Verdier (2000) or Hauk \& Saez-Marti (2002), multiple equilibria arise due to failures in the expectations coordination. Then, the implementation of public policies or the commitment from authorities may be a solution to these inefficiencies. In that sense, our setting provides a new instrument to authorities in order to reach, for instance, any environmental or development fixed target. Typically, the government may ensure the achievement of its objective by shaping the median voter's feature and coordinating individual expectations. For instance, the success of any environmental policy, which aims at reducing environmental deterioration, could be realised, at least partially, if authorities are capable of coordinating agents' beliefs on quite optimistic expectations with respect to the environment it-self.

However, notice that achieving such objective might not be Pareto-improving. Indeed, the welfare analysis leads to ambiguous results due to the existence of heterogeneous agents: it is then tricky to rank both equilibria. On the one hand, the high equilibrium $E^{s}$ always seems to be preferred by skilled workers: first, the implemented tax is exactly the one they vote for; 
second, environmental quality is higher. However, even if unskilled individuals benefit from a better environmental quality in $E^{s}$, they have to pay an undesirable and higher tax $\tau^{s}$. Then, the high equilibrium might not be optimal for unskilled workers. A governmental policy that would aim at reaching $E^{S}$ and escaping the trap, might not be Pareto-optimal, if the taxation effect dominates the green benefits. Nevertheless, since the level of development is also higher in $E^{s}$, we will consider such an objective and assess the instrument to achieve it.

\section{Policy implications}

Let us now study the opportunity for an economy to escape from the environmental trap. As mentioned above, an improved environmental quality and a higher level of development are reached, at the steady-state, if agents coordinate on optimistic expectations, thus being more likely to educate. Consequently, in order to step out from the trap, the government may aim at encouraging agents to invest in additional human capital. Among the various available instruments, we consider that the government reduces the fixed cost of education $(\lambda)$ in order to boost the share of highly educated workers within the population. Here, as education is time consuming, the decrease of $\lambda$ includes all improvements made in order to ameliorate the "learning technology": a better access to school, an increase in the size of teaching profession, etc....

Let consider that initially the economy is pinned-down to $E^{u}$, the environmental trap such that $E^{u}<\bar{E}$. At date $T$, the government announces that taxes collected are now used for two alternative purposes: environmental maintenance and education. More precisely, the authorities decide to devote a share $\alpha \in(0,1)$ of public receipt to environmental maintenance, while the remaining taxes $(1-\alpha)$ will be invested in education at next date. Obviously, at date $T$, the share of both skilled and unskilled agents within the population is unaffected while occupational choices of next generations will depend on the level of the "subsidy" to education. However, agents' behaviour is instantaneously altered when dealing with the optimal poll tax and therefore, the environmental quality law of motion evolves from date $T+1$.

In order to assess the impact of such kind of public policy, we first describe the changes that occur during the transition phase at date $T$; then, we expose the resulting dynamics of the economy when the policy is fully implemented, from date $T+1$.

\subsection{Transition phase}

The governmental action has a direct effect on the future environmental quality, which enters the utility function of agents born at date $T$. Differently from (6), environmental quality evolves now according to:

$$
E_{T+1}=(1-\eta) E_{T}-P_{T}+\beta\left(\alpha \tau_{T}\right)^{\theta},
$$

where $P_{T}$ is given, provided that the value of $\tilde{z}_{T}$ is associated with the equilibrium value of $E^{u}$ in the previous model. Notice that the share of public revenue devoted to education does not affect agents' behaviour born at date $T$ with respect to occupational choices; they only suffer the "green" side of the public policy.

Provided that the level of technology is given and constant over time, agents maximise (1), under (2), (4) and (27) in order to determine the new optimal poll tax, noted with superscript $p$ that stands for policy. Notice that the design of the policy $(\alpha)$ is taken as given when agents 
determine their optimal willingness-to-pay. Agents do not vote on the distribution of the tax among the two purposes (which are either education or environmental maintenance), but only the level of the tax. It yields for an individual of type- $i$ :

$$
\tau^{p, i}=\left(\beta \pi^{i} \theta \alpha^{\theta}\right)^{\frac{1}{1-\theta}} .
$$

This result captures the positive and one-way correlation between the share of tax revenue dedicated to environmental expenditure and the level of the tax: an increase in $\alpha$ fosters the investment in environmental maintenance. Otherwise said, since extra education is not triggered by any altruistic motive, a larger share of receipt devoted to education does not provide any additional gain of utility, but only a smaller incentive to invest in maintenance. Finally, compared to the benchmark model, for both types of agents, the willingness-to-pay for improving environmental conditions is smaller, since $\alpha<1$.

Under the assumption of stationary expectations, the dynamics are described by the following system:

$$
E_{T+1}= \begin{cases}\Omega_{u}\left(E_{T}\right) & \text { if } E_{T+1}<\tilde{E} \\ \Omega_{s}\left(E_{T}\right) & \text { if } E_{T+1} \geq \tilde{E},\end{cases}
$$

where $\Omega_{i}\left(E_{T}\right)$ describe the transitional dynamics of environmental quality. As we focus mainly on the outcome of the public policy starting from $E^{u}$, we only describe the new dynamics characterized by an originally unskilled majority of workers. Formally, using (10), (14), (27) and (28), it yields:

$$
\Omega_{u}\left(E_{T}\right)= \begin{cases}\left.(1-\eta) E_{T}-\gamma A^{u}+\beta\left(\alpha \tau^{p, u}\right)^{\theta}\right] & \text { if } E_{T+1} \leq \check{E} \\ \frac{A^{s}\left[(1-\eta) E_{T}+\beta\left(\alpha \tau^{p, u}\right)^{\theta}\right]-\gamma(1-\lambda)\left(A^{s^{2}}+A^{u^{2}}\right)+\gamma A^{u} A^{s}(1-2 \lambda)}{A^{s}+\gamma\left(A^{s}-A^{u}\right)\left(\pi^{s}-\pi^{u}\right)} & \text { if } \check{E}<E_{T+1}<\tilde{E}\end{cases}
$$

Lemma 2 Starting from $E^{u} \in[\underline{E}, \bar{E}]$, if the government implements a public policy in favour of education at date $T$, environmental quality deteriorates at date $T+1$.

Proof. The slope of $\Omega_{u}\left(E_{T}\right)$ is identical to the slope of $\Psi_{u}\left(E_{t}\right)$, for all $E_{t}$. However, $\Omega_{u}(0)<$ $\Psi_{u}(0)$. Thus, $\Omega_{u}\left(E_{T}\right)$ crosses the $45^{\circ}$ line before $E^{u}$.

As depicted in Figure 5, starting from the low equilibrium $E^{u}$, at date $T+1$, the economy ends up in $\breve{E}$, defined such that $\Omega_{u}\left(E^{u}\right)=\breve{E}(\alpha)$. In fact, in the benchmark model, the whole revenue collected by the government is devoted to environmental maintenance. As soon as the public policy is implemented, the aggregate level of maintenance provided by authorities is reduced. Obviously this implies that environmental quality decreases compared to the initial situation, since pollution flows are constant. However, the value of environmental quality at date $T+1$ increases with $\alpha$ : the larger the share granted to environmental protection, the better the environment.

\subsection{Long-run dynamics}

Equation (27) describing the law of motion of the environment holds as soon as the public policy is implemented. However, from now on, the generation born at date $T+1$ benefits from the subsidy to education $\left(v_{t}\right)$ and so the proportion of skilled and unskilled workers in 


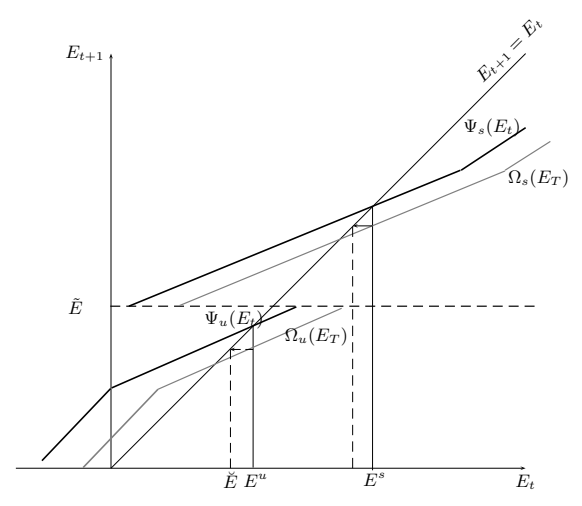

Figure 5: First phase of transition

the economy might change. Provided that the technology is invariant over time, the budget constraint for both types of agents is now given by the following system:

$$
\left\{\begin{array}{l}
y_{T+1}^{s}=\left[1-\left(1-v_{T+1}\right) \lambda-z\right] w^{s} \\
y_{T+1}^{u}=\left[1-\left(1-v_{T+1}\right) \lambda\right] w^{u}
\end{array}\right.
$$

where $v_{t} \in[0,1]$. The government's budget constraint is unchanged (see equation (5)), while the education subsidy is financed thanks to taxes collected at the previous date, so that:

$$
v_{T+1}=\left[(1-\alpha) \tau_{T}^{p, i}\right]^{\kappa},
$$

where $\kappa \in[0,1]$. Consistently with the benchmark model, we consider that $\kappa$ reveals the efficiency of the learning technology: investing in schooling facilities exhibits decreasing marginal returns, meaning that it is easier to improve the educational system when the latter is not that much advanced. Moreover, this parameter could also capture the effectiveness of the tax collection, as previously. A higher value of $\kappa$ would then imply that tax revenue are slightly dissipated in collection costs.

Similarly to our benchmark model, and in order to determine their own optimal poll tax, agents maximise their utility (1), under (27) and (31). Solving this program yields the result already exposed in equation (28).

The investment in education is still shaped by the comparison of indirect utilities but now, using (1), (31) and (4), the threshold value on the private cost of education, $z$, writes as:

$$
\tilde{z}_{T+1}^{p}=\frac{\left(A^{s}-A^{u}\right)\left[1-\left(1-\nu_{T+1}\right) \lambda\right]+\left(\pi^{s}-\pi^{u}\right) E_{T+2}^{a}}{A^{s}}
$$

Obviously, the positive effect of optimistic agents' expectations is preserved; in addition, we can show that the higher the subsidy, the greater the threshold education cost. This implies mechanically that agents with a higher individual education cost, who would have been unskilled in the basic model, may now invest in extra education. As previously, $\tilde{z}_{T+1}^{p}$ accounts for the 
share of skilled workers within the economy, so that if $E_{T+2}^{a} \geq \hat{E}^{p} \equiv \frac{A^{u}-\left(A^{s}-A^{u}\right) \lambda\left(1-v_{T+1}\right)}{\left(\pi^{s}-\pi^{u}\right)}, \tilde{z}_{T+1}^{p}$ equals unity; if expectations are much more pessimistic, that is $E_{T+2}^{a} \leq \breve{E}^{p} \equiv \frac{\left(A^{s}-A^{u}\right)\left[\left(1-v_{T+1}\right) \lambda-1\right]}{\left(\pi^{s}-\pi^{u}\right)}$, then $\tilde{z}_{T+1}^{p}=0$.

As we focus on a specific configuration, that is a starting point in $E^{u}$, we can directly deduce the value of $v_{T+1}$ and the resulting threshold value on $\tilde{z}_{T+1}^{p}$. Indeed, at the previous date the majority was still unskilled, and so the poll tax was equal to $\tau^{p, u 10}$. It follows that:

$$
v_{T+1}=\left[(1-\alpha) \tau^{p, u}\right]^{\kappa},
$$

and

$$
\tilde{z}_{T+1}^{p}=\frac{\left(A^{s}-A^{u}\right)\left[1-\left(1-\left[(1-\alpha) \tau^{p, u}\right]^{\kappa}\right) \lambda\right]+\left(\pi^{s}-\pi^{u}\right) E_{T+2}^{a}}{A^{s}}
$$

This threshold value depends ambiguously on the parameter $\alpha$, which captures the design of the policy. On the one side, a small value of $\alpha$, thus inducing a larger subsidy to education, may trigger the investment in additional education and increase the share of skilled agents in the economy. On the other side, notice that $\alpha$ influences also, in the opposite way, the level of the tax, and the resulting subsidy. As already mentioned through equation (28), a smaller share of public receipt granted to environmental protection reduces the willingness-to-pay and, ultimately, the fiscal revenue.

Similarly to Subsection 2.1, anticipations with respect to the future environment will determine the long-run dynamic implications of the model. To determine which tax prevails in the economy, we proceed as in subsection 2.2. Hence, we can state that:

$$
\left\{\begin{array}{l}
\tau_{T+1}=\tau^{p, u} \text { if } E_{T+2}^{a}<\tilde{E}^{p}(\alpha) \\
\tau_{T+1}=\tau^{p, s} \text { if } E_{T+2}^{a} \geq \tilde{E}^{p}(\alpha)
\end{array}\right.
$$

where

$$
\tilde{E}^{p}(\alpha) \equiv \frac{A^{s}-2\left(A^{s}-A^{u}\right)\left[1-\left(1-\left[(1-\alpha) \tau^{p, u}\right]^{\kappa}\right) \lambda\right]}{2\left(\pi^{s}-\pi^{u}\right)}
$$

Notice that $\tilde{E}^{p}(\alpha)<\tilde{E}$. The crucial idea here is that expectations' feature (be it optimistic or pessimistic) depends on $\alpha$, that is the subsidy to education. Yet, if we consider the following derivative

$$
\frac{\partial \tilde{E}^{p}(\alpha)}{\partial \alpha}=\frac{(\alpha-\theta) \kappa \lambda\left(A^{s}-A^{u}\right)\left[(1-\alpha) \tau^{p, u}\right]^{\kappa}}{(1-\alpha)(1-\theta) \alpha A^{s}\left(\pi^{s}-\pi^{u}\right)}
$$

which sign depends on the distance between $\alpha$ and $\theta$, we can see that $\alpha$ plays a key role. Again, the impact of $\alpha$ is twofold: on the one hand, a larger value of the parameter $\alpha$, thus inducing a smaller subsidy to education, might slacken the investment in education and increase the share of unskilled agents in the economy. In that case, expectations have to be very optimistic (i.e., $E_{T+2}^{a}$ very high) to allow for the majority to become skilled; on the other hand, if the subsidy is very large, the share of highly educated workers within the population grows, and even if expectations are relatively pessimistic, they can more easily allow the majority to be highly educated.

10. Notice that now the threshold value on $z$ at date $T+1$ may take two different values according to the tax prevailing at date $T$. As we focus on a specific case, we do not present the alternative value of $\tilde{z}_{T+1}^{p}$ when the tax equals $\tau^{p, s}$ at date $T$. 
This paves the way for an eventual optimal allocation of the public receipt among education and environmental maintenance, according to the goal which is pursued. If the aim of the government is to boost the extra investment in education, then the share devoted to maintenance should reduce slightly.

Once again, starting from the low equilibrium at date $T$ and depending on the median voter's feature, we are able to characterize the dynamics of the economy. When the median voter is unskilled, we define $E_{T+2} \equiv \phi_{u}\left(E_{T+1}, E_{T+2}^{a}\right)$ and formally, using (14), (27), (35) and (36), we obtain:

$$
\phi_{u}\left(E_{T+1}, E_{T+2}^{a}\right)= \begin{cases}(1-\eta) E_{T+1} & \text { if } E_{T+2}^{a} \leq \check{E}^{p} \\ (1-\eta) E_{T+1}-P\left(E_{T+2}^{a}\right)+\beta\left(\alpha \tau^{p, u}\right)^{\theta} & \text { if } E_{T+2}^{a}>\check{E}^{p} .\end{cases}
$$

When the median voter is highly educated, we have $E_{T+2} \equiv \phi_{s}\left(E_{T+1}, E_{T+2}^{a}\right)$ such that

$$
\phi_{s}\left(E_{T+1}, E_{T+2}^{a}\right)= \begin{cases}(1-\eta) E_{T+1}-P\left(E_{T+1}^{a}\right)+\beta\left(\alpha \tau^{p, s}\right)^{\theta} & \text { if } E_{T+2}^{a} \geq \hat{E}^{p} \\ (1-\eta) E_{T+1}-\gamma A^{s}+\beta\left(\alpha \tau^{p, s}\right)^{\theta} & \text { if } E_{T+2}^{a}<\hat{E}^{p} .\end{cases}
$$

Finally, the global dynamics can be summarized by the following system:

$$
E_{T+2}= \begin{cases}\phi_{u}\left(E_{T+1}, E_{T+2}^{a}\right) & \text { if } E_{T+2}^{a}<\tilde{E}^{p} \\ \phi_{s}\left(E_{T+1}, E_{T+2}^{a}\right) & \text { if } E_{T+2}^{a} \geq \tilde{E}^{p}\end{cases}
$$

As before, we consider rational expectations implying that $E_{T+2}^{a}=E_{T+2}$. Then, we can characterize a perfect foresight dynamics by solving (39) and (40), for $E_{T+2}^{a}=E_{T+2}$. This assumption allows us to obtain a one dimensional dynamical system, that describes the evolution of environmental quality from date $T+1$ (see Appendix D):

$$
E_{T+2}= \begin{cases}\Phi_{u}\left(E_{T+1}\right) & \text { if } E_{T+2}<\tilde{E}^{p}(\alpha) \\ \Phi_{s}\left(E_{T+1}\right) & \text { if } E_{T+2} \geq \tilde{E}^{p}(\alpha)\end{cases}
$$

Similarly to the benchmark model, we can claim that, under proper conditions, each dynamic trajectory, $\Phi_{u}\left(E_{T}\right)$ or $\Phi_{s}\left(E_{T}\right)$ taken separately, admits only one globally stable steady-state, $E^{p, u}$ and $E^{p, s}$, characterized by a low and a high environmental quality, respectively. Moreover, assuming that expectations are no longer stationary, then there exists an area of indeterminacy when $E^{p, u}$ and $E^{p, s}$ belong to the interval $\left[\underline{E}^{p}, \bar{E}^{p}\right]$. In that case, expectations might be selffulfilling.

In particular, we have:

$$
E^{p, u}=\frac{\beta A^{s}\left(\alpha \tau^{p, u}\right)^{\theta}+A^{s} A^{u} \gamma(1-2 \lambda)-\gamma(1-\lambda)\left(A^{s^{2}}+A^{u^{2}}\right)-\gamma \lambda\left(A^{s}-A^{u}\right)^{2}\left[(1-\alpha) \tau^{p, u}\right]^{\kappa}}{\gamma\left(A^{s}-A^{u}\right)\left(\pi^{s}-\pi^{u}\right)+\eta A^{s}}
$$

and

$$
E^{p, s}=\frac{\beta A^{s}\left(\alpha \tau^{p, s}\right)^{\theta}+A^{s} A^{u} \gamma(1-2 \lambda)-\gamma(1-\lambda)\left(A^{s^{2}}+A^{u^{2}}\right)-\gamma \lambda\left(A^{s}-A^{u}\right)^{2}\left[(1-\alpha) \tau^{p, s}\right]^{\kappa}}{\gamma\left(A^{s}-A^{u}\right)\left(\pi^{s}-\pi^{u}\right)+\eta A^{s}}
$$

Notice that $E^{p, u}<E^{u}$ and $E^{p, s}<E^{s}$, since $\tau^{i^{\theta}}>\left(\alpha \tau^{p, i}\right)^{\theta}$. Introducing this new policy that aims at stimulating additional education lowers the stationary values of environmental quality. However, this kind of public policy may become very relevant when the objective of the government is to escape from the low equilibrium, $E^{u}$. 


\subsection{Out of the trap}

Let us recall that when $\alpha=1$, then $\bar{E}^{p}=\bar{E}$ and $E^{u}=\breve{E}$. Yet, starting from a situation where $\bar{E}>E^{u}$ and the economy is stuck in the environmental trap, it is possible for the government to implement a public policy such that $E_{T+2}=\breve{E}(\alpha)>\bar{E}^{p}(\alpha)$. Then, the economy may reach the high equilibrium $E^{p, s}$. In other words, this implies that the majority must be skilled and so more prone to engage maintenance expenditure. The parameter $\alpha$ seems to be a relevant and available instrument to achieve this target: the share of public receipt devoted to environmental maintenance, and consequently to education, plays a crucial role by determining the median voter's feature.

Depending on the situation at date $T+1$, we can claim that, as shown in Figure 6:

Proposition 3 Starting from $E^{u}$ and under proper conditions, for $\alpha \in\left[\alpha_{1}, \alpha_{2}\right]$, with $\alpha_{1}<\alpha_{2}<1$, it could be the case that, at date $T+2, \bar{E}^{p}(\alpha)<\breve{E}(\alpha)$. Then, the economy jumps to the optimistic trajectory described by $\Phi_{s}\left(E_{T+1}\right)$ and, in the long-run, the economy may reach the high equilibrium, $E^{p, s}$.

\section{Proof. See Appendix E}

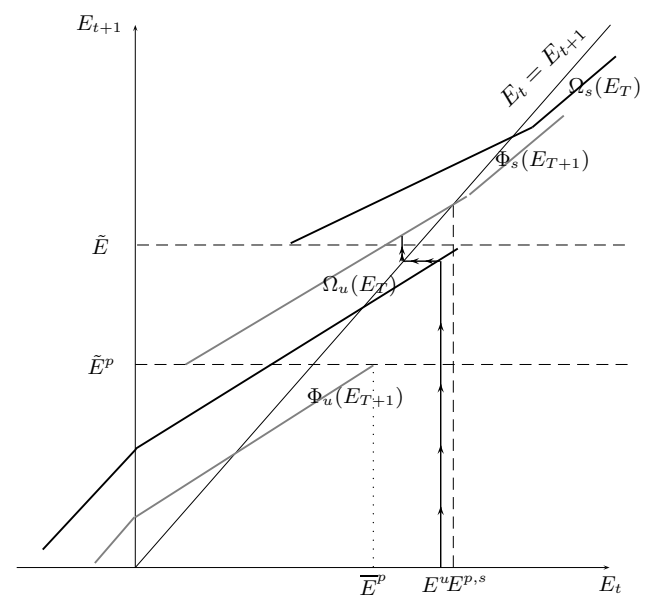

Figure 6: Policy

There exists a set of values of $\alpha, \alpha \in\left[\alpha_{1}, \alpha_{2}\right]$, so that the economy jumps on the optimistic trajectory, which is unique and may attain, in the long-run, the stable stationary value $E^{p, s}$. Indeed, starting from $E^{u}$, at date $T$, environmental quality deteriorates and the economy ends up in $\breve{E}(\alpha)$, since the policy only reduces incentives to expand in environmental protection. Then, from $T+1$, the public policy affects agents' occupational choices; a new dynamics arise. If the area of existence of $\Phi_{s}\left(E_{T+1}\right)$ is sharply reduced, then there is no more indeterminacy. As depicted in Figure 6, from date $T+2$, the economy follows directly the trajectory of $\Phi_{s}\left(E_{T+1}\right)$. In that case, the majority within the population is skilled and so exhibits a higher willingness- 
to-pay. The public policy is efficient and the economy escapes from the trap. Let us now study under which condition on the design of the public policy, this configuration may occur.

Let us recall that $\breve{E}(\alpha)$ is an increasing function of $\alpha$, while the effect of the latter are ambiguous on the existence area of $\Phi_{u}\left(E_{T+1}\right)$. Indeed, if the share devoted to maintenance is very large, then incentives to educate are very weak and in addition, expectations are more likely to be pessimistic. Hence, obviously $\Phi_{u}\left(E_{T+1}\right)$ exists for greater values of $E_{t}$. On the contrary, if $\alpha$ is very small, then environmental quality at date $T+1$ is very low. Although, a larger subsidy boosts the extra investment in education, it turns out that, the latter effect dominates the former one. When the government chooses to grant a large amount of public receipt to education, the policy may become inefficient and $\bar{E}^{p}(\alpha)>\breve{E}(\alpha)$. Finally, for extreme values of $\alpha$, the public policy might be inefficient.

Even if the public policy is still endogenous, the authorities may intervene in order to stimulate education. Starting from a low environmental quality, the economy may experience a non-monotonous convergence towards the high equilibrium. Following the implementation of the public policy, at first environmental quality deteriorates but then, if the policy design is efficient, the environment may improve and the proportion of highly educated agents within the society increases. However, as mentioned above, the stationary values of environmental quality when the policy is implemented are lower than in the benchmark case, that is when education is not subsided. Therefore, it may be the interest of the government to implement a temporary policy, in order to reach ultimately the highest equilibrium $E^{S}$.

Corollary 2 A temporary public policy in favour of education may allow the economy to select the highest steady-state $E^{s}>E^{p, s}$, and so have long-lasting consequences.

Once the economy reaches the optimistic trajectory $\Phi_{s}\left(E_{T+1}\right)$, then it seems possible to return on the initial optimistic trajectory, described by $\Psi_{s}\left(E_{t+1}\right)$, in order to attain the highest equilibrium, $E^{S}$. In fact, if $E^{S}$ does not belong to $[\underline{E}, \bar{E}]$, then, it is optimal at some specific point in time to stop the public policy and to devote all resources to environmental maintenance $(\alpha=1)$. Obviously, the economy attains a higher stationary value, since incentives to contribute for environmental maintenance are stronger, and the share of highly educated agents is larger. Nevertheless, when $E^{s}$ belongs to $[\underline{E}, \bar{E}]$, only under the assumption of stationary expectations, the government may also reach a higher stationary value.

The main message of this kind of policy is that educating the population may be a mean to improve in the long-run the overall situation, including environmental quality. This kind of conclusion may be related with some experimental studies dealing with the education, the information about environmental risks, or environmental protection. (see, for instance, Jalan \& Somanathan (2008))

\section{Conclusion}

In this paper we have studied the interaction between the political and economic decisions of agents. Agents decide wether to invest in additional human capital or not, according to their expectations regarding future environmental quality. Two types of workers co-exist within the population, some of them being skilled, the others unskilled. Once, their occupational choices are made, they vote for a poll tax that will be used to finance environmental protection and the 
level of the effective implemented tax depends finally on the median voter's feature. First, under the hypothesis of rational and constant expectations, the model may provide multiplicity of equilibria. Then, we show that agent's expectations may be self-fulfilling when public policy is endogenised: for instance, if agents coordinate on optimistic expectations with regards to the future environment, they are likely to invest in additional education, display a higher willingness-to-pay for environmental protection, and the economy reaches in the long-run, the higher equilibrium, and conversely. We also underline that, because of this expectation-driven multiplicity of equilibria, the model offers a property of indeterminacy. This paves the way for a public policy implementation, in order to coordinate expectations on one specific outcome. Finally, the level of education and environmental quality are positively correlated in the long-run.

Our model also proposes to investigate the opportunities of a public intervention in order to select a higher equilibrium. In this respect, we model the dynamic implications of a subsidy to education. We show that under specific conditions on the policy' design, reducing the fixed cost of education may allow for reaching the high equilibrium. Moreover, we are able to identify the temporary character of the public policy, although its effects are long-lasting.

Finally, as interesting extensions for further research, we would suggest (i) to explore alternative public policies suitable for the selection of one outcome, (ii) to introduce other policy options that would allow for coordinating agent's expectations and (iii) to enhance the realistic dimension of the model, by endogeneizing, for instance, technological progress. 


\section{References}

Andreoni, J., \& Levinson, A. 2001. The simple analytics of the environmental Kuznets curve. Journal of Public Economics, 80, 269-286.

Barro, R., \& Sala-i Martin, X. 1995. Economic Growth. Mc Graw-Hill: New-York.

Bimonte, S. 2002. Information acess, income distribution and the environmental Kuznets curve. Ecological Economics, 41, 145-156.

Bisin, A., \& Verdier, T. 2000. A model of cultural transmission, voting and political ideology. European Journal of Political Economy, 16, 5-29.

Brock, W., \& Taylor, M. Scott. 2005. Economic Growth and the Environment: A Review of theory and empirics. Durlauf, s. and aghion, p. edn. Handbook of Economic Growth.

Carlsson, F., \& Johansson-Stenman, O. 2000. Willingness to pay for improved air quality in Sweden. Applied Economics, 32, 661-669.

Caselli, F. 1999. Technological revolutions. The American Economic Review, 89, 78-102.

Cervellati, M., \& Sunde, U. 2005. Human capital formation, life expectancy, and the process of development. The American Economic Review, 95(5), 1653-1672.

Chakraborty, S. 2004. Endogneous Lifetime and Economic Growth. Journal of Economic Theory, 116, 119-137.

CID. 2000. International Data on Educational Attainment: Updates and Implications. Tech. rept. Center for International Developmenrt at Harvard University.

de la Croix, D., \& Licandro, O. 2007. The child is father of the man: implications for the demographic transition. Mimeo.

Farzin, H.Y., \& Bond, C.A. 2006. Democracy and environmental quality. Journal of Development Economics, 81, 213-235.

Fershtman, C., K.M., Murphy, \& Weiss, Y. 1996. Social Status, Education and Growth. Journal of Political Economy, 104, 108-132.

Fredriksson, Per G., Neumayer, E., Damania, R., \& Gates, S. 2005. Environmentalism, democracy, and pollution control. Journal of Environmental Economics and Management, 49, 343-365.

Galor, O., \& Moav, O. 2000. Ability biased technological transition, wage inequality within and across groups, and economic growth. Quarterly Journal of Economics, 115, 469-497.

Glomm, G., \& Ravikumar, B. 1995. Endogenous public policy an dmultiple equilibria. European Journal of Political Economy, 11, 653-662.

Goetz, Stephan J., Debertin David L. Pagoulatos Angelos. 1998. Human capital, income, and environmental quality: a state-level analysis. Agricultural and Resource Economics Review, 27(2), 200-208. 
Hauk, E., \& Saez-Marti, M. 2002. On the cultural transmission of corruption. Journal of Economic Theory, 107, 311-335.

Ikefuji, Masako, \& Horii, Ryo. 2007. Wealth Heterogeneity and Escape From the PovertyEnvironment Trap. Journal of Public Economic Theory, 9(6), 1041-1068.

Jalan, J., \& Somanathan, E. 2008. The importance of being informed: experimental evidence on the demand for environmental quality. Journal of Development Econmoics, 87, 14-28.

John, A., \& Pecchenino, R. 1994. An Overlapping Generations Model of Growth and the Environment. The Economic Journal, 104(427), 1393-1410.

Jouvet, P-A., Michel, P., \& Pestieau, P. 2008. Public and private environmental spending. A political economy approach. Environmental Economics and Policy Studies, 9.

Lightart, J.E, \& Ploeg, F. Van Der. 1999. Environmental policy, tax incidence, and the cost of public funds. Environmental and Resources Economics, 13, 187-207.

Lleras-Muney, A. 2005. The relationship between education and adult mortality in the UnitedStates. Review of Economic Studies, 72, 189-221.

Magnani, E. 2000. The environmental Kuznets curve, environmental protection policy and income distribution. Ecological Economics, 32, 431-443.

Mariani, F., Perez barahona, A., \& Raffin, N. 2009. Life expectancy and the environment. Miméo.

Ono, T. 2002. The effects of Emission permits on Growth and the environment. Environmental and Resource Economics, 21, 75-87.

Pfaff, A., Chauddhuri, S., \& Nye, H. 2004. Endowments, preferences, technologies and abatement: growth-environment microfundations. International Journal of Global Environmental Isues, 4, 209-228.

Plassmann, F., \& Khanna, N. 2006. Prefernces, technology, and the environment: understanding the environmental Kuznets curve. American JOurnal of Agricultural Economics, 88(3), 632-643.

Renström, T, \& Marsiliani, L. 2002. Inequality, environmental Portection and growth. Working Paper No. 35.

Saint Paul, G., \& Verdier, T. 1997. Power, distributive conflicts, and multiple growth paths. Journal of Economic Growth, 2(June), 155-168.

YCELP. 2006. Environmental Performance Index. Tech. rept. Yale Center for Environmental Law and Policy. 


\section{A Proof of lemma 1}

The dynamic system is described by equation (22) and explicitly by both (23) and (24). Let us now determine the conditions of existence and stability of the steady-states, $E^{u}$ and $E^{s} . \Psi_{u}\left(E_{t}\right)$ is increasing and piecewise linear in $E_{t}$. The slope of the function belongs to the range $[0,1]$. It follows that the solution of the equation $E_{t}=\Psi_{u}\left(E_{t}\right)$ is unique and globally stable. We denote this steady-state $E^{u}$. Hence, when $E_{t}>\Psi_{u}\left(E_{t}\right)(<)$, environmental quality deteriorates (improves).

Similarly, $\Psi_{s}\left(E_{t}\right)$ is increasing and piecewise linear in $E_{t}$. The slope of the function belongs to the range $[0,1]$. It follows that the solution of the equation $E_{t}=\Psi_{s}\left(E_{t}\right)$ is unique and globally stable. We denote this steady-state $E^{s}$. Hence, when $E_{t}>\Psi_{s}\left(E_{t}\right)(<)$, environmental quality deteriorates (improves).

\section{B Proof of proposition 1}

Let us determine under which conditions multiplicity may arise.

In order to determine the area of existence of each dynamics, we need to define two threshold values on $E_{t}$. First, $\Psi_{u}\left(E_{t}\right)$ exists for all $E_{t+1}<\tilde{E}$. Then, we define $\bar{E}$ such that $\Psi_{u}\left(E_{t}\right)=\tilde{E}$. It follows that:

$$
\bar{E}=\frac{\gamma\left(A^{s}+A^{u}\right)+\left(A^{u}-A^{s}\right)(1-2 \lambda)+A^{u}-2 \beta \tau^{u^{\theta}}}{2(1-\eta)\left(\pi^{s}-\pi^{u}\right)}
$$

Then, $\Psi_{u}$ exists for all $E_{t}<\bar{E}$. Similarly, $\Psi_{s}\left(E_{t}\right)$ exists for all $E_{t+1} \geq \tilde{E}$. Then, we define $\underline{E}$ such that $\Psi_{s}\left(E_{t}\right)=\tilde{E}$. Using equation (B.1) and substituting $\tau^{u}$ by $\tau^{s}$ yields the value of $\underline{E}$. Obviously, since $\tau^{\mathcal{S}}>\tau^{u}$, then $\bar{E}>\underline{E}$. Finally, $\Psi_{s}$ exists for all $E_{t}>\underline{E}$.

(i) $\bar{E}>\underline{E}>E^{s}>E^{u}$.

For $E_{t}>\overline{\bar{E}}$, the unique perfect foresight is described by $\Psi_{s}\left(E_{t}\right)$. Since, for $E_{t}>E^{s}$, environmental quality deteriorates, ultimately it becomes lower than $\bar{E}$. For $E_{t} \in[\bar{E}, \underline{E}]$, there exist two trajectories compatible with perfect expectations: $E_{t+1}=\Psi_{u}\left(E_{t}\right)$ or $E_{t+1}=\Psi_{s}\left(E_{t}\right)$. Since, $E_{t}>E^{s}>E^{u}$, environmental quality deteriorates, whatever the trajectory and becomes ultimately lower than $\bar{E}$. For $E_{t}<\bar{E}$, the unique perfect foresight path is described by $E_{t+1}=\Psi_{u}\left(E_{t}\right)$. Hence, through Lemma (1), the economy converges towards $E^{u}$.

(ii) $E^{s}>E^{u}>\bar{E}>\underline{E}$.

For $E_{t}<E$, the unique perfect foresight is described by $\Psi_{u}\left(E_{t}\right)$. Since, for $E_{t}<E^{u}$, environmental quality improves, ultimately it becomes larger than $\underline{E}$. For $E_{t} \in[\bar{E}, \underline{E}]$, there exist two trajectories compatible with perfect expectations: $E_{t+1}=\Psi_{u}\left(E_{t}\right)$ or $E_{t+1}=\Psi_{s}\left(E_{t}\right)$. Since, $E_{t}<$ $E^{S}<E^{u}$, environmental quality improves, whatever the trajectory and becomes ultimately larger than $\bar{E}$. For $E_{t}>\bar{E}$, the unique perfect foresight path is described by $E_{t+1}=\Psi_{s}\left(E_{t}\right)$. Hence, through Lemma (1), the economy converges towards $E^{S}$.

(iii) $\bar{E}>E^{S}>E^{u}>\underline{E}$

For any $E_{0}<\tilde{E}, \Psi_{u}\left(E_{t}\right)$ describes the dynamics of the economy: the equilibrium reached is $E^{u}$. Conversely, for any $E_{0} \geq \tilde{E}$, the dynamics of the economy is described by $\Psi_{s}\left(E_{t}\right)$ and the equilibrium attained is $E^{S}$. 


\section{Proof of Proposition 2}

Both $\Psi_{S}\left(E_{t}\right)$ and $\Psi_{u}\left(E_{t}\right)$ are monotonically increasing in $E_{t}$ (see proof of Lemma 1). hence, for $E_{t} \in[\bar{E}, \underline{E}], \Psi_{s}\left(E_{t}\right) \geq \Psi_{s}(\underline{E})=\tilde{E}$ and $\Psi_{u}\left(E_{t}\right) \leq \Psi_{u}(\bar{E})=\tilde{E}$. Consequently, if agents expect that the median voter will be skilled in $t+1: E_{t+1}=\Psi_{u}\left(E_{t}\right) \leq \tilde{E}$ and the median voter is effectively skilled. In a similar way, if agents expect that the median voter will be unskilled, $E_{t+1}=\Psi_{s}\left(E_{t}\right) \geq \tilde{E}$, and expectations are then self-confirmed.

\section{Dynamic implications of the public policy}

The dynamics are described by equation (42). Let us now determine the conditions of existence and stability of the steady-states, $E^{p, u}$ and $E^{p, s} . \Phi_{u}\left(E_{T+1}\right)$ is increasing and piecewise linear in $E_{T}$. The slope of the function belongs to the range $[0,1]$. It follows that the solution of the equation $E_{T+2}=\Phi_{u}\left(E_{T}\right)$ is unique and globally stable. We denote this steady-state $E^{p, u}$. Hence, when $E_{T}>\Phi_{u}\left(E_{T}\right)(<)$, environmental quality deteriorates (improves).

Similarly, $\Phi_{s}\left(E_{T}\right)$ is increasing and piecewise linear in $E_{T}$. The slope of the function belongs to the range $[0,1]$. It follows that the solution of the equation $E_{T+2}=\Psi_{S}\left(E_{T+1}\right)$ is unique and globally stable. We denote this steady-state $E^{p, s}$. Hence, when $E_{T}>\Psi_{s}\left(E_{T}\right)(<)$, environmental quality deteriorates (improves).

Let us determine under which conditions multiplicity may arise.

We define two threshold values on $E_{T}$. First, $\Phi_{u}\left(E_{T+1}\right)$ exists for all $E_{T+2}<\tilde{E}^{p}$. We determine define $\bar{E}^{p}$ such that $\Phi_{u}\left(E_{T+1}\right)=\tilde{E}^{p}$. It follows that:

$$
\bar{E}^{p}=\frac{\gamma\left(A^{s}+A^{u}\right)+\left(A^{u}-A^{s}\right)(1-2 \lambda)-2 \beta\left(\alpha \tau^{p, u}\right)^{\theta}\left(\pi^{s}-\pi^{u}\right)-2 \lambda\left(A^{s}-A^{u}\right)\left[(1-\alpha) \tau^{p, u}\right]^{\kappa}}{2(1-\eta)\left(\pi^{s}-\pi^{u}\right)}
$$

Then, the dynamics is described by $E_{T+2}=\Phi_{u}$ for all $E_{t}<\bar{E}^{p}$. Similarly, $\Phi_{s}\left(E_{T+1}\right)$ holds for all $E_{T+2} \geq \tilde{E}^{p}$. Then, we define $\underline{E}^{p}$ such that $\Phi_{s}\left(E_{T+1}\right)=\tilde{E}^{p}$. Using equation (D.1) and substituting $\tau^{p, u}$ by $\tau^{p, s}$ yields the value of $\underline{E}^{p}$. Obviously, since $\tau^{p, s}>\tau^{p, u}$, then $\bar{E}^{p}>E^{p}$. Finally, $\Phi_{s}\left(E_{T+1}\right)$ holds for $E_{t}>\underline{E}^{p}$.

Once these two thresholds are defined, the dynamics exhibit the same properties as the one described in Appendix B. Then, if we consider that expectations are no longer stationary, we can define an area of indeterminacy, if $E^{p, s}$ and $E^{p, u}$ belong to $\left[\underline{E}^{p}, \bar{E}^{p}\right]$.

\section{E Proof of Proposition 3}

In this appendix we aim at showing that for some values of $\alpha$, it could be the case that $\breve{E}(\alpha)>$ $\bar{E}^{p}(\alpha)$, thus implying that the implemented policy allows from escaping the low equilibrium.

First, let us study the properties of $\breve{E}(\alpha)$.

$$
\begin{gathered}
\breve{E}(\alpha)=\frac{\gamma A^{s} A^{u}(1-2 \lambda)-\gamma(1-\lambda)\left(A^{s^{2}}+A^{u^{2}}\right)+A^{s}(1-\eta) E^{u}+A^{s} \beta\left(\alpha \tau^{p, u}\right)^{\theta}}{A^{s}+\gamma\left(A^{s}-A^{u}\right)\left(\pi^{s}-\pi^{u}\right)} \\
\breve{E}(0)=\frac{\gamma A^{s} A^{u}(1-2 \lambda)-\gamma(1-\lambda)\left(A^{s^{2}}+A^{u^{2}}\right)+A^{s}(1-\eta) E^{u}}{A^{s}+\gamma\left(A^{s}-A^{u}\right)\left(\pi^{s}-\pi^{u}\right)}
\end{gathered}
$$




$$
\breve{E}(1)=\frac{\gamma A^{s} A^{u}(1-2 \lambda)-\gamma(1-\lambda)\left(A^{s^{2}}+A^{u^{2}}\right)+A^{s}(1-\eta) E^{u}+A^{s} \beta\left(\tau^{p, u}\right)^{\theta}}{A^{s}+\gamma\left(A^{s}-A^{u}\right)\left(\pi^{s}-\pi^{u}\right)},
$$

with $\breve{E}(1)>\breve{E}(0)$. Moreover $\breve{E}(\alpha)$ is increasing and monotonous over the range $\alpha \in[0,1]$.

Second, let us analyse the properties of $\bar{E}^{p}(\alpha)$ and then study the impact of the parameter $\alpha$ on this threshold value.

$$
\bar{E}^{p}(0)=\frac{\gamma\left(A^{s}+A^{u}\right)+(1-2 \lambda)\left(A^{u}-A^{s}\right)}{2(1-\eta)\left(\pi^{s}-\pi^{u}\right)+A^{u}}
$$

and

$$
\bar{E}^{p}(1)=\frac{\gamma\left(A^{s}+A^{u}\right)+(1-2 \lambda)\left(A^{u}-A^{s}\right)-2 \beta\left(\pi^{s}-\pi^{u}\right)\left(\tau^{p, u}\right)^{\theta}}{2(1-\eta)\left(\pi^{s}-\pi^{u}\right)+A^{u}}
$$

with $\bar{E}^{p}(0)>\bar{E}^{p}(1)$.

$$
\frac{\partial \bar{E}^{p}}{\partial \alpha}=\frac{\left[-\beta\left(\pi^{s}-\pi^{u}\right)(1-\alpha) \theta\left(\alpha \tau^{p, u}\right)^{\theta}+\lambda\left(A^{s}-A^{u}\right) \kappa(\alpha-\theta)\left[(1-\alpha) \tau^{p, u}\right]^{\kappa}\right]}{(1-\eta) \alpha\left(\pi^{s}-\pi^{u}\right)(1-\theta)(1-\alpha)}
$$

The sign of $\frac{\partial \bar{E}^{p}}{\partial \alpha}$ depends on the value of $\alpha$. Let us define $g(\alpha)=\alpha^{\frac{(1-\kappa) \theta}{1-\theta}} \beta\left(\pi^{\mathcal{s}}-\pi^{u}\right) \theta\left(\beta \pi^{u} \theta\right)^{\frac{\theta-\kappa}{1-\theta}}$ and $f(\alpha)=\lambda\left(A^{s}-A^{u}\right) \kappa(\alpha-\theta)(1-\alpha)^{\kappa-1}$. Then,

$$
\operatorname{sign}\left\{\frac{\partial \bar{E}^{p}}{\partial \alpha}\right\}=\operatorname{sign}\{g(\alpha)-f(\alpha)\}
$$

Studying the properties of each function, we can define $\alpha^{*}$ such that: $f(\alpha)>g(\alpha)(<)$, for $\alpha>\alpha^{*}(<)$.

Indeed, $g(0)=0, g^{\prime}(\alpha)>0$ and $\lim g(\alpha)_{\alpha \rightarrow 1}=\beta\left(\pi^{\varsigma}-\pi^{u}\right) \theta\left(\beta \pi^{u} \theta\right)^{\frac{\theta-K}{1-\theta}}$ is finite. Moreover, $f(0)<0$, and $\lim f(\alpha)_{\alpha \rightarrow 1}=+\infty$. The sign of $f^{\prime}(\alpha)$ is positive for $0<\alpha<1$ if $\frac{1-\theta(1-\kappa)}{\kappa}<1$. Yet, this conditions is always satisfied since $k<1$. Then, $f^{\prime}(\alpha)>0$. Finally, $g(\alpha)$ and $f(\alpha)$ cross only once and we define $\alpha^{*}$ such that: $f\left(\alpha^{*}\right)=g\left(\alpha^{*}\right)$.

We can deduce that if $\alpha>\alpha^{*}(<)$, then $\frac{\partial \bar{E}^{p}}{\partial \alpha}>0(<)$. Hence the thresholds $\bar{E}^{p}(\alpha)$ draws a u-shaped pattern.

Finally, $\breve{E}(\alpha)$ and $\bar{E}^{p}(\alpha)$ may cross twice of the slope of $\breve{E}(\alpha)$ is lower than the slop of $\bar{E}^{p}(\alpha)$ for $\alpha=1$. We have shown that $\partial \breve{E}(\alpha) /\left.\partial \alpha\right|_{\alpha=1}$ is finite while $\partial \bar{E}^{p}(\alpha) /\left.\partial \alpha\right|_{\alpha=1}$ is infinite. Then we can claim that:

$$
\left.\frac{\partial \breve{E}(\alpha)}{\partial \alpha}\right|_{\alpha=1}<\left.\frac{\partial \bar{E}^{p}(\alpha)}{\partial \alpha}\right|_{\alpha=1}
$$

Then, if the distance between $\bar{E}^{p}(1)$ and $\breve{E}(1)$ is not too large, the two functions may cross twice, thus defining two threshold values, $\alpha_{1}$ and $\alpha_{2}$, with $\alpha_{1}<\alpha_{2}$. In that case, $\bar{E}^{p}(\alpha)<\breve{E}(\alpha)$ for $\alpha \in\left(\alpha_{1}, \alpha_{2}\right)$. In that case only, the policy will be efficient and allows the economy to jump directly on the optimistic trajectory, $\Phi_{s}\left(E_{T+2}\right)$. On the contrary, if the distance between $\bar{E}^{p}(1)$ and $\breve{E}(1)$ is too large, then the two functions do not cross, and the policy is never efficient. 